\title{
Percentage body fat and prevalence of obesity in a UK offshore population
}

\author{
BY I. M. LIGHT ${ }^{1}$ AND M. GIBSON 2 \\ Robert Gordon's Institute of Technology, ${ }^{1}$ Offshore Survival Centre and ${ }^{2}$ Department \\ of Mathematics and Computing Studies, 352 King Street, Aberdeen AB9 2TQ
}

(Received 27 January 1986 - Accepted 18 February 1986)

\begin{abstract}
1. Body-weight, body height and skinfold measurements were taken in 419 adult males working in the UK offshsore oil industry. Percentage body fat was estimated from skinfold thicknesses and the Quetelet index (weight: height ${ }^{2}$ ) determined.

2. The prevalence of overweightness, assessed from the Quetelet index, in the age groups 20-29, 30-39 and 40-49 years was $31 \cdot 6,50 \cdot 0$ and $66.2 \%$ respectively. The Office of Population Census and Surveys (1981) showed that for age-matched groups, the incidence of overweightness in an onshore population was 26,40 and $50 \%$ respectively.

3. The percentage body fat for each respective age group was greater than that reported for an age-matched onshore population.

4. The Quetelet index was significantly related to body fat $(r 0.765, P<0.0001)$ and poorly correlated with height, thus this weight: height relation may be utilized in the assessment of overweightness in offshore personnel.

5. In conclusion it appears that the offshore population had a higher percentage body fat than their onshore peers and that the prevalence of overweightness was also greater.
\end{abstract}

The fat content of the human body has received considerable attention, and numerous population studies have been undertaken (MacMillan et al. 1965; Haisman, 1970; Durnin \& Womersley, 1974; Gooderson \& Beebee, 1976). The advent of offshore oil development has resulted in a workforce living and working in what has been considered a hostile environment (Golden, 1976). Since the workforce is largely captive and few facilities exist that allow for active leisure time, a considerable degree of social activity is based on the canteen or refectory. Furthermore, considerable quantities of food of high quality are readily available and no limits are applied in respect of intake.

During exploration and construction phases, high levels of activity and energy expenditure might be expected. The production phase, however, involves work of a more sedentary nature. The possibility, therefore, of energy intake being greater than energy expenditure would result in deposition of fat, leading to a greater percentage of jody-weight as fat. The suggestion of both mariners and offshore oil workers having more subcutaneous fat has recently been made (Hayward \& Eckerson, 1984).

There is little doubt that the rate of body heat loss and subsequent cooling rate in cold water is inversely related to skinfold thickness and percentage body fat (Carlson et al. 1958; Keatinge, 1960). In the event of an accidental immersion in the North Sea, survival time may be significantly extended in individuals possessing greater amounts of body fat.

An occupational group working in the North Sea that has received much attention is the commercial diver (Crosbie et al. 1977; McCallum \& Petrie, 1984). Obesity is one of the factors taken into consideration in deciding whether or not a man is medically fit to dive. Prospective and retrospective research conducted on groups of commercial and military divers has suggested a relation between adiposity and the occurrence of decompression sickness (Dembert et al. 1984). Analysis of weight records of 1520 divers suggested that divers as a group were substantially heavier than other populations on whom height-weight tables have been based. A recent comparison between North Sea divers and a sedentary UK onshore population (Thompson et al. 1984) did not demonstrate any significant differences between height, weight, Quetelet index or maximal aerobic power. 
The objectives of the present study were to estimate the body fat content and the prevalence of overweightness in personnel working in an offshore environment and to compare the results to other studies of onshore populations. The paper describes the height, weight, percentage body fat, Quetelet index and the prevalence of overweightness and obesity in a sample of 419 adult males.

\section{MATERIALS AND METHODS}

Subjects

The Offshore Survival Centre of Robert Gordon's Institute of Technology has trained many thousands of personnel in the techniques of maritime survival. Each week some 350 trainees attend courses at the establishment. This has ensured a population representative of that working in the North Sea. The subjects were 419 Caucasian males resident in Great Britain and engaged in employment in the UK North Sea Sectors.

Each week's intake at the Centre is allocated to one of seven courses of varying duration. Every tenth person on the roll call registers was asked to participate in the study and, provided they satisfied the above criteria, were included in the trial. Measurements were equally divided between morning and afternoon and the information was collected between April and June 1984.

\section{Procedures}

Subjects were assembled in groups after having the study explained to them. Height $(\mathbf{H})$ was measured to the nearest $5 \mathrm{~mm}$ in bare feet using a wall-mounted anthropometer. Weight (W) was read to the nearest $0 \cdot 1 \mathrm{~kg}$ with the subjects wearing only underpants, using a calibrated Weylux Beam Balance.

Skinfold measurements were taken with the Harpenden constant force caliper (British Indicators Ltd, Harpenden, Herts) from the biceps, triceps, subscapular and suprailiac sites as described by Durnin \& Womersley (1974). All skinfolds were measured by one of the authors (IL). The percentage of body-weight as fat $(\% \mathrm{BF})$ was calculated from skinfolds using age-related coefficients and by the substitution of density estimates in the equation of Siri (1956).

\section{RESULTS}

Table 1 shows the physical characteristics, Quetelet index $\left(\mathrm{W}: \mathrm{H}^{2}\right)$ and skinfold thickness of the 419 males measured in the study. The subjects in the survey had been engaged in offshore employment for a mean of 4.2 (SD 3.8) years. The number of subjects in each of the following age groups: up to $20,20-29,30-39,40-49$ and greater than 50 years were $4,180,144,77$ and 14 respectively. The age groups were chosen to coincide with those of Durnin \& Womersley (1974).

The Quetelet index $v$. the subject's height is shown in Fig. 1. Linear regression analysis produced a correlation coefficient of $-0 \cdot 169$. The Quetelet index is shown $v$. the subject's age in Fig. 2. Linear regression analysis resulted in a regression equation of the form $\mathrm{W}: \mathrm{H}^{2}=0 \cdot 132$ (age) $+20 \cdot 552$. The correlation coefficient $(r 0 \cdot 364)$ was statistically significant $(t 7.97, P<0.001)$. The population distribution for the Quetelet index is shown in Fig. 3. Grades 0,1 and 2 are those according to the classification of Garrow (1981) and show that for the sample considered as a whole some $40.1 \%$ may be considered overweight and that an additional $5.5 \%$ of the sample are obese. Closer examination of the results in the present study shows that in each age group the prevalence of overweightness was $31 \cdot 6,50 \cdot 5$ and $66.2 \%$ for the age groups $20-29,30-39$ and $40-49$ years respectively. The prevalence of 
Table 1. Physical characteristics, Quetelet index (weight: height ${ }^{2}$ ) and skinfold thicknesses of the sample population ( $\mathrm{n} 419$ )

(Mean values and standard deviations)

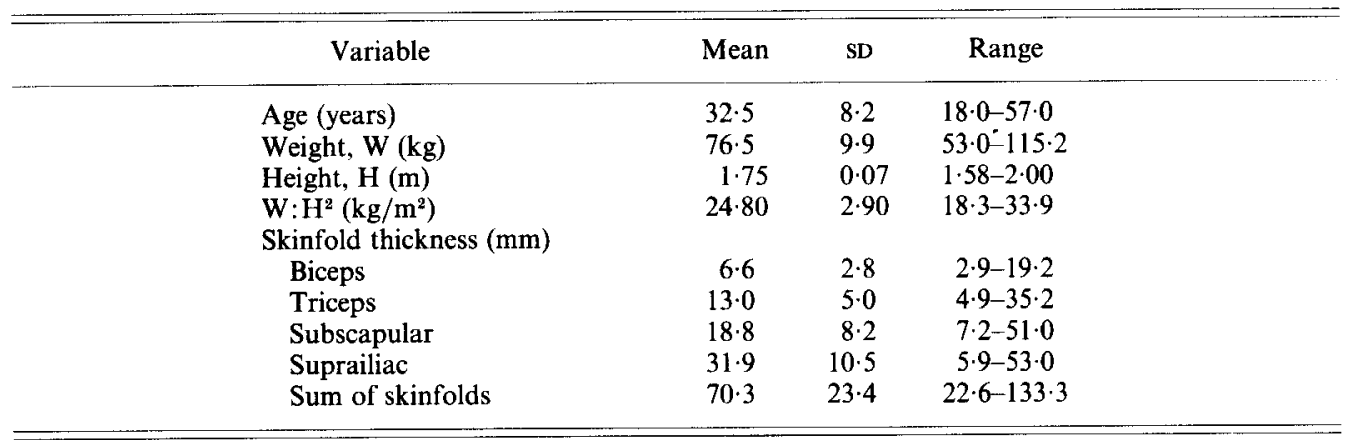

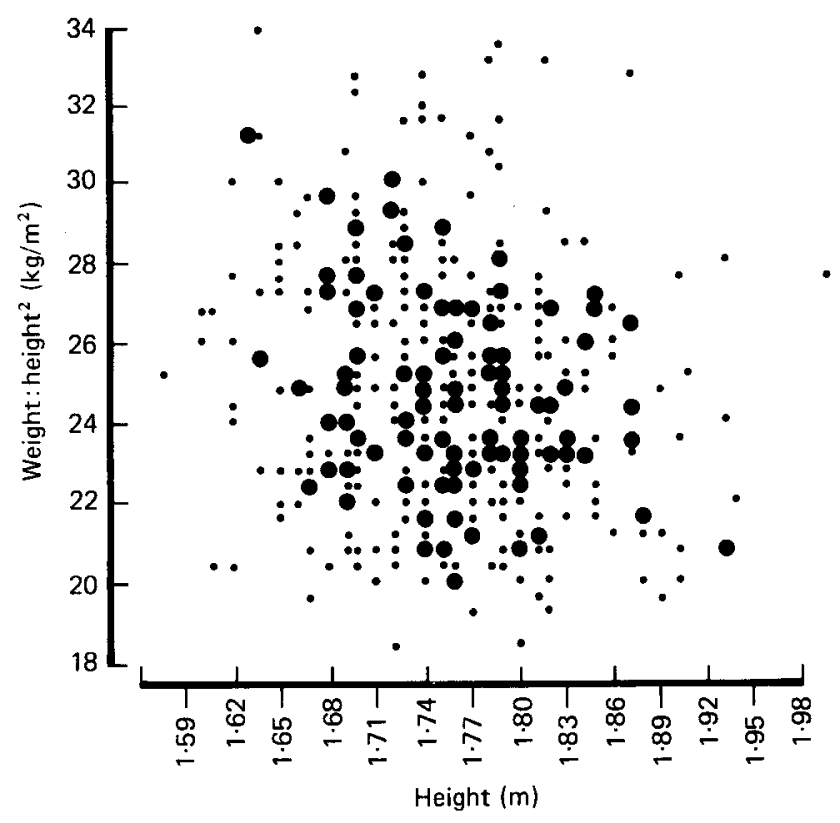

Fig. 1. Individual values for Quetelet index (weight:height ${ }^{2}$ ) and height. (๑), one observation; (O), > one observation.

overweightness in the three age groups was then compared with the incidence reported by the Office of Population Census Surveys (OPCS) (1981). The extreme age groups, i.e. under 20 years and above 50 years were excluded from the analysis since the cell frequencies were too small for that required for a valid $\chi^{2}$ test. The observed prevalence (for the present study) was compared with the expected prevalence (OPCS, 1981). The $\chi^{2}$ statistic (9.88) showed that the incidence of overweightness was significantly greater $(P<0.05)$ than that identified in the general population.

The percentage body fat (BF) $v$. age is shown in Fig. 4. Linear regression analysis demonstrated a highly significant correlation coefficient of $r 0.654(t 17.7, P<0.0001)$. The 


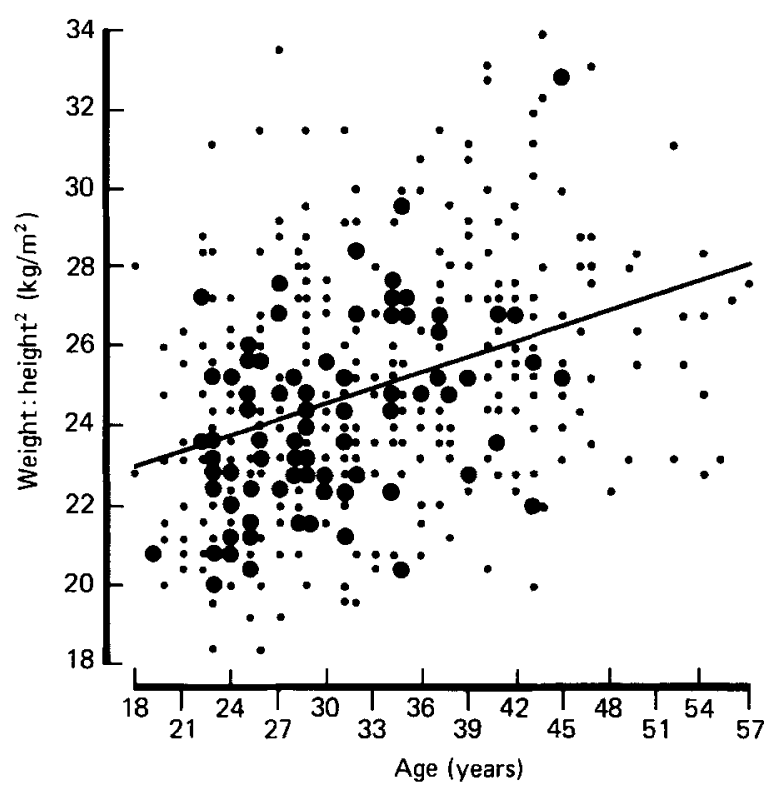

Fig. 2. Individual values for Quetelet index (weight height ${ }^{2} ; \mathrm{W}: \mathrm{H}^{2}$ ) and age with best-fit regression line of the form $\mathrm{W}: \mathrm{H}^{2}=0.132$ (age) $+20.552(t 7.97, P<0.0001)$. (๑), one observation; $(\bullet)$, $>$ one observation.

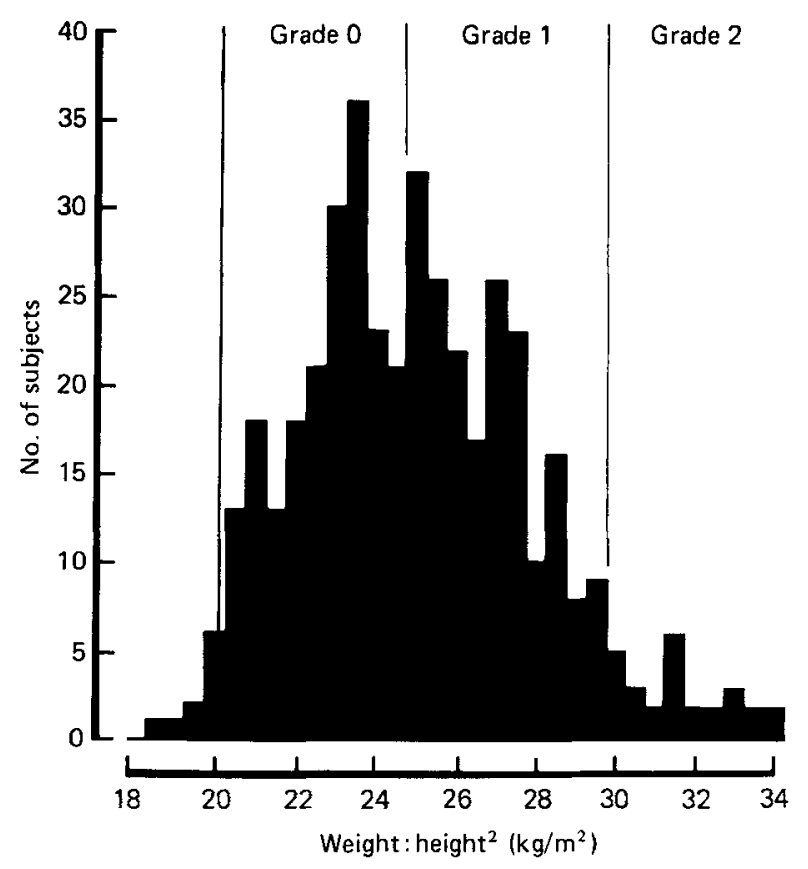

Fig. 3. Distribution of Quetlet index for an offshore male population ( $n$ 419). Quetelet index values of $20-24.9,25-29.9$ and $30-40$ may be used to define obesity as grades 0,1 and 2 respectively (Garrow, 1981). 


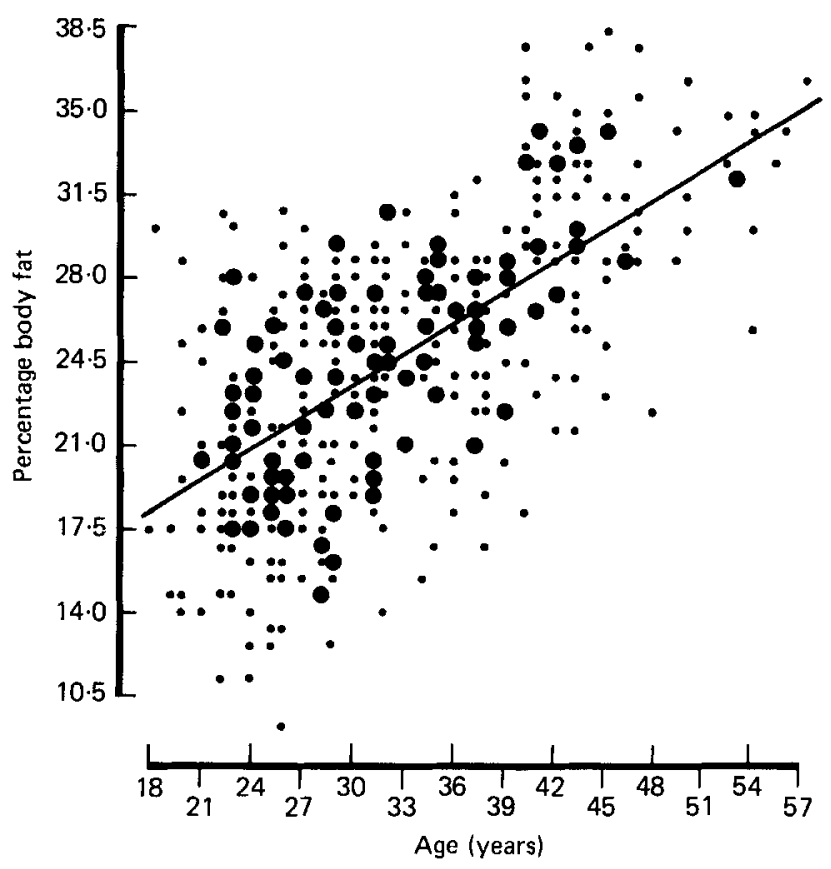

Fig. 4. Individual values for percentage body fat (BF) (determined from skinfold thicknesses) and age with best fit regression line of the form $\% \mathrm{BF}=0.442$ (age) $+10.225(n 419)$. ( $)$, one observation; ( $)$, $>$ one observation.

Table 2. Heights $(H)$, weights $(W)$ and $\%$ body fat $(B F)$ of the subjects in the present study, classified in age groups and shown with values from earlier studies

(Mean values and standard deviations)

\begin{tabular}{|c|c|c|c|c|c|c|c|}
\hline \multirow{2}{*}{$\begin{array}{l}\text { Age group } \\
\text { (years) }\end{array}$} & & \multicolumn{2}{|c|}{$\begin{array}{c}\text { Durnin \& Womersley } \\
\qquad(1974)\end{array}$} & \multicolumn{2}{|c|}{$\begin{array}{c}\text { Rosenbaum } \text { et al. } \\
(1985)\end{array}$} & \multicolumn{2}{|c|}{$\begin{array}{c}\text { Present study } \\
\text { (measured in 1984) }\end{array}$} \\
\hline & & Mean & SD & Mean & $n$ & Mean & $\mathrm{SD}$ \\
\hline $20-29$ & $\begin{array}{l}\mathrm{H}(\mathrm{m}) \\
W(\mathrm{~kg}) \\
\% \mathrm{BF} \\
n\end{array}$ & $\begin{array}{c}1 \cdot 77 \\
70 \cdot 1 \\
15 \cdot 0\end{array}$ & $\begin{array}{c}0.069 \\
12.2 \\
7.0\end{array}$ & $\begin{array}{l}1 \cdot 76 \\
72 \cdot 2\end{array}$ & $\begin{array}{l}1158 \\
1057\end{array}$ & $\begin{array}{l}1 \cdot 77 \\
74 \cdot 9 \\
21 \cdot 20\end{array}$ & $\begin{array}{l}0 \cdot 069 \\
9 \cdot 8 \\
4 \cdot 6\end{array}$ \\
\hline $30-39$ & $\begin{array}{l}\mathrm{H}(\mathrm{m}) \\
\mathrm{W}(\mathrm{kg}) \\
\% \mathrm{BF} \\
n\end{array}$ & $\begin{array}{l}1 \cdot 76 \\
79 \cdot 8 \\
23 \cdot 0\end{array}$ & $\begin{array}{c}0.056 \\
10 \cdot 4 \\
5 \cdot 4\end{array}$ & $\begin{array}{c}1 \cdot 75 \\
75 \cdot 3\end{array}$ & $\begin{array}{r}1098 \\
982\end{array}$ & $\begin{array}{c}1 \cdot 74 \\
76 \cdot 4 \\
25 \cdot 0\end{array}$ & $\begin{array}{l}0.069 \\
9.0 \\
3.5\end{array}$ \\
\hline $40-49$ & $\begin{array}{l}\mathrm{H}(\mathrm{m}) \\
\mathrm{W}(\mathrm{kg}) \\
\% \mathrm{BF} \\
n\end{array}$ & $\begin{array}{l}1.75 \\
76 \cdot 0 \\
25 \cdot 0\end{array}$ & $\begin{array}{l}0 \cdot 070 \\
9 \cdot 2 \\
6 \cdot 7\end{array}$ & $\begin{array}{c}1 \cdot 74 \\
76 \cdot 9\end{array}$ & $\begin{array}{l}937 \\
839\end{array}$ & $\begin{array}{l}1.74 \\
80 \cdot 4 \\
30 \cdot 4\end{array}$ & $\begin{array}{c}0.061 \\
11 \cdot 1 \\
4 \cdot 3\end{array}$ \\
\hline
\end{tabular}


regression equation was of the form $\% \mathrm{BF}=0.442$ (age) $+10 \cdot 225$. The mean values of $\% \mathrm{BF}$, height and weight for each age group are shown against the results of Durnin \& Womersley (1974) and Rosenbaum et al. (1985) in Table 2.

\section{DISCUSSION}

An earlier study on the estimation of body fat from skinfold measirements (Durnin \& Womersley, 1974) provided useful information on height, weight and percentage body fat that have been compared with the results reported in the present study. In comparing populations it is important that they are matched for age and age groupings. Numerous authors have used either 5- or 10-year classification methods. The recent publication of the survey of heights and weights of adults in Great Britain (Rosenbaum et al. 1985) measured in 1980 facilitates comparison with the present study. Durnin \& Womersley (1974) neither attempted to obtain nor required a random sample of the population and their study may have contained a preponderance of moderately sedentary middle-class men. Values reported by OPCS (1981), taken in 1980, were representative of adults in the age range 16-64 years. The subjects' mean height in each group was similar in the three studies and demonstrated a decrease in height with age. With the exception of the 30-39 years age group of Durnin \& Womersley (1974), all age groupings in the present study demonstrated increased mean body-weights above those of the other studies.

The Quetelet index $\left(\mathrm{W}: \mathrm{H}^{2}\right)$ has been used extensively in population surveys. The use of the Quetelet index requires that it should have a poor correlation with height but significant correlation with body fat $(r-0.169$ and $r 0.765$ in the present study). Garrow (1981) has suggested that Quetelet index values of $20-24 \cdot 9,25-29 \cdot 9,30-40 \cdot 0$ and greater than 40 may be used to define obesity into grades $0,1,2$ and 3 respectively. In the present study it is possible to classify $45.6 \%$ of the population measured as being overweight of which $5.5 \%$ may be considered obese. OPCS (1981), using Garrow's gradings, showed that $33 \%$ of the UK population in their sample may be considered to have excess weight and a further $6 \%$ to be obese. OPCS (1981) for the age groups 20-29, 30-39 and 40-49 years indicated the incidence of overweightness for these age groups as 26,40 and $50 \%$ respectively. These values are significantly less than the observed values of $31.6,50.5$ and $66.2 \%$ in the present study ( $\chi^{2}$ test, $P<0.05$ ). The incidence of obesity, however, was comparable.

The increase in body-weight with age appears to follow the increase in the percentage of the body-weight as fat. Before interpreting and comparing the percentage body fat values it is important to recognize the limitation of the method used.

Determination of percentage body fat from skinfold thickness measurements are only estimates of percentage body fat. Underwater weighing techniques are considered more accurate but are time consuming and not applicable for a large-scale population as recruited in this survey. Whilst there are definite limitations in the use of skinfold thickness as an estimate of percentage body fat, close correlation has been previously demonstrated between densitometric and skinfold techniques (Durnin \& Womersley, 1974). Durnin \& Womersley (1974) have reported percentage body fat values of 15,23 and 25 for age grouping 20-29, 30-39 and 40-49 years respectively. In the present study the derived percentage body fat was increased within each age classification to levels of $21 \cdot 2,25 \cdot 0$ and $30.4 \%$ respectively.

The increased levels of body fat and the prevalence of overweightness as determined by the Quetelet index in the age-matched population reported in the present paper may be the result of the interplay of many factors. Offshore employment requires the person to be continually at his place of work for either 7,14 or $21 \mathrm{~d}$. Following his work schedule he may then have a comparable leave period ashore. It is worth considering the social and 
behavioural aspects of weight gain. Meals are a major social function and the food intake of an individual is affected by the community in which he lives. This is particularly the case in the offshore environment where most social activity is based on the canteen and meal time. Considerable quantities of food of good quality, constant availability and minimal control over issue may induce over-eating.

The fat content of the body depends ultimately on the balance between energy intake and energy output. During the study the subjects were asked to estimate their energy expenditure at work and few subjects reported their job to require a high level of energy expenditure. The energy balance of offshore workers has not been reported and may well provide useful information relating energy input to energy expenditure and the possible imbalance.

In addition to the weekly or fortnightly shifts the working day is typically $12 \mathrm{~h}$ working and $12 \mathrm{~h}$ off duty. Very few of the subjects in the present study participated in any form of active leisure-time pursuit during their offshore phase and reported that after a $12 \mathrm{~h}$ shift they did not feel like indulging in physical activity. The provision of exercise facilities and mini-gymnasia was by no means universal. The nature of the environment was not conducive to active dynamic exercise although some dedicated individuals did partake in such activities as roller cycling, ergometer cycling, Canadian Airforce programme calisthenics and gymnasium workouts.

There are certain financial incentives in offshore employment and this may result in a greater level of disposable income being available during the onshore phase. Increased food consumption during this phase may also contribute to the increased body-weights recorded in this study.

It would seem desirable that a longitudinal study evaluating the effects of the above factors on body-weight and fat content of offshore employees be established. Since the trainees are likely to return for 'refresher' training after some 2-3 years have elapsed, the opportunity would exist to repeat the measurements reported in the present study.

The study has shown that the percentage body-weight as fat in the offshore worker was indeed greater than values reported for onshore personnel and that the prevalence of overweightness was also higher. The significant correlation between the Quetelet index and percentage body fat suggested that in the absence of skinfold thickness measurements the simple $\mathrm{W}: \mathrm{H}^{2}$ value might be used as an indication of both obesity and body fat. To ensure accuracy and standardization, the measurements should be made with the person in bare feet and wearing only underclothes. Since height and weight are normally recorded, this technique would be eminently suitable for use during a routine medical examination.

\section{REFERENCES}

Carlson, L. D., Hsieh, A. C. L., Fullington, F. \& Elsner, R. W. (1958). Aerospace Medicine 29, $142-152$. Crosbie, W. A., Clarke, M. B., Cox, R. A. F., Mclver, N. K. I., Anderson, I. K., Evans, H. A., Liddle, G. C., Cowan, J. L., Brookings, A. H. \& Watson, D. G. (1977). British Journal of Industrial Medicine 34, 19-25.

Dembert, M. L., Jekel, J. F. \& Mooney, L. W. (1984). Aviation Space and Environmental Medicine 55, 391-395. Durnin, J. V. G. A. \& Womersley, J. (1974). British Journal of Nutrition 32, 77-97.

Garrow, J. S. (1981). In Recent Advances in Medicine no. 18, pp. 75-92 [A. M. Dawson, N. Compston and G. M. Besser, editors]. Edinburgh and London: Churchill Livingstone.

Golden, F. St. C. (1976). Journal of the Society of Occupational Medicine 26, 85-88.

Gooderson, C. Y. \& Beebee, M. (1976). Anthropometry of 500 Infantrymen 1973-74. Army Personnel Research Establishment report no. 17/76. London: H.M. Stationery Office.

Haisman, M. F. ( 1970). Human Biology 42, 679-688.

Hayward, J. S. \& Eckerson, J. D. (1984). Aviation Space and Environmental Medicine 55, 206-212.

Keatinge, W. R. (1960). Journal of Physiology 153, 166-173.

McCallum, R. I. \& Petrie, A. (1984). British Journal of Industrial Medicine 41, 275-278. 
MacMillan, M. G., Reid, C. M., Shirling, D. \& Passmore, R. (1965). Lancet i, 728-729.

Office of Population Census and Surveys (1981). OPCS Monitor, ref. SS 81/1. St. Catherine's House, London: Government Statistical Service.

Rosenbaum, S., Skinner, R. K., Knight, I. B. \& Garrow, J. S. (1985). Annals of Human Biology 12, $115-127$. Siri, W. E. (1956). University of California Radiation Laboratory publication no. 3349. Berkley: University of California.

Thompson, J., Barr, D., McDonald, D. R. \& Rennie, M. J. (1984). Lancet i, 52. 